\title{
COVID-19 in Different Age Groups of Children: Initial Impression from Integrated Disease Surveillance Programme (IDSP) under National Centre for Disease Control (NCDC)
}

\author{
Sanket Vasant Kulkarni ${ }^{1} \cdot$ Himanshu Chauhan ${ }^{1}$ \\ Received: 15 July 2020 / Accepted: 15 July 2020 / Published online: 23 July 2020 \\ (C) Dr. K C Chaudhuri Foundation 2020
}

COVID-19 was first reported from Wuhan, Hubei Province in China in the month of December 2019 and was then referred to as a 'Viral Pneumonia of Unknown Aetiology'. It soon spread to many countries across the world and was eventually labelled as a 'Pandemic' by WHO on 11th March 2020. The first case of COVID-19 was reported from India in the last week of January 2020. As on 8th July 2020, the country has reported more than 7.5 lakh cases and 21,000 deaths with a case fatality rate of approximately $3 \%$ [1].

\section{Emergence of COVID-19 in India}

COVID-19 came into the country with the movement of International passengers and gradually made its way in the country. A pattern indicating early cases among International travellers and then to their close contacts and finally to the community has been observed in majority of the States. The disease is currently being reported by all States and UTs of India except Lakshadweep. The cases have been reported across all age groups, affecting infants as well as the elderly, men and women; girls and boys none have been spared. The clinical presentation of COVID-19 has been quite varied with a wide spectrum of signs and symptoms ranging from asymptomatic cases to predominantly respiratory illness, flu-like symptoms, GI symptoms and other non-specific presentations. The cases have also varied in terms of severity of the illness with majority of the cases being mild and a few very severe requiring ICU admissions with ventilatory support.

Sanket Vasant Kulkarni

sanket.kulkarni@gov.in

1 IDSP, NCDC, Ministry of Health \& Family Welfare, New Delhi, India
The case fatality rate of the disease also varies across the States ranging from $0 \%$ to $6 \%$.

A closer look at the available data, reveals that the economically productive age group i.e., $21-50$ contributes to the maximum proportion $(60 \%)$ of the total cases in the Country. This is followed by those below $20 \mathrm{y}$ of age constituting nearly $13 \%$ of the cases reported from India. Males contribute to $66 \%$ of the total positive cases as well as a similar proportion of deaths. It has also been observed that $3 \%$ of the total deaths reported from India are among those below $20 \mathrm{y}$ of age.

Information on clinical presentation and disease severity among neonates is very limited and based on case reports from few States. The reported signs among the limited number of neonates with confirmed SARS-CoV-2 infection included fever, cough, tachypnea, strenuous breathing, vomiting, diarrhea, lethargy, rhinorrhea, and feeding difficulties. The extent to which SARS-CoV-2 infection contributed to the reported signs of infection and complications is however a subject of further detailed research.

As per the data reported by various States and Union Territories through the Integrated Disease Surveillance Programme (IDSP) [2] under National Centre for Disease Control (NCDC) [3], majority of the cases among children are more than $5 \mathrm{y}$ of age. There are very few reported cases in children less than $5 \mathrm{y}$ of age which may be due to inadequate testing in this age group. This in turn could be due to absence of typical symptoms in children, lack of awareness among the general public or a lower index of suspicion among the pediatricians. There have been reports of multisystem inflammatory disorders among children infected with SARS-CoV-2 from western countries and WHO has developed a preliminary case definition and case report form for the same.

To conclude, the situation is still evolving with lots of unknowns about the virus and its manifestations, especially among the pediatric age group. There is a need for careful 
documentation and critical analysis of various aspects of this novel disease and also sharing this information with all stakeholders.

\section{Compliance with Ethical Standards}

Conflict of Interest None.

\section{References}

1. https://www.mohfw.gov.in/

2. https://idsp.nic.in/

3. https://www.ncdc.gov.in/

Publisher's Note Springer Nature remains neutral with regard to jurisdictional claims in published maps and institutional affiliations. 